\section{The NCCN Older Adult Oncology Panel Remembers Arti Hurria}

\author{
Efrat Dotan, MD and Louise C. Walter, MD
}

$\mathbf{O}$ November 7, 2018, the NCCN Older Adult Oncology Panel and the geriatric oncology community as a whole lost a tremendous leader, mentor, and scientist with the passing of Arti Hurria, MD, in a tragic accident. As the NCCN Older Adult Panel mourns the loss of Dr. Hurria, we felt compelled to write about her outstanding contributions to our field and to each of us personally.

Dr. Hurria transformed the field of geriatric oncology. She was the thought leader and early pioneer of this critical field of research and clinical care. Her dedication to this field is evident in every area of her work, through establishing and leading the Cancer and Aging Research Group (CARG), spearheading efforts in this field through ASCO, co-chairing the Elderly Committee for Alliance Cancer, and leading the International Society of Geriatric Oncology (SIOG). June M. McKoy, MD, MBA, JD, MPH, from Robert H. Lurie Comprehensive Cancer Center of Northwestern University stated, "Arti believed that there should be no obstacle to enrolling older adults in cancer clinical trials. She established CARG, which has successfully enrolled these patients in cancer-specific clinical trials. Quod erat demonstrandum."

Dr. Hurria also recognized the importance of reaching out to all stakeholders (including the FDA and $\mathrm{NCl}$ ) promoting research in the field of geriatric oncology. Peggy Burhenn, MS, RN, a Geriatric Oncology Clinical Nurse Specialist at City of Hope National Medical Center, recalled Dr. Hurria's support for all members of the multidisciplinary team and remembered Dr. Hurria saying, "Caring for older adults is a complex problem that requires input from all members of the team. If you want to go fast, go alone, and if you want to go far, go together." Dr. Hurria had exceptional leadership abilities in bringing people together and uniting them under a common goal. Ashley Rosko, MD, from The Ohio State University Comprehensive Cancer Center - James Cancer Hospital and Solove Research Institute noted, "She created and led a community in her spirit: self-less, dedicated, and compassionate. She was a mentor, advisor, friend, [and] collaborator to so many, and her ability to lead an entire field and create an infrastructure to sustain the work is incredible."

Dr. Hurria was instrumental in shaping the NCCN Guidelines for Older Adult Oncology (previously known as "Senior Adult Oncology"). She served as the chair of the panel between 2011 and 2016 and led the restructure of the guidelines. These guidelines raise awareness of the unique assessment and treatment considerations that are required when caring for older patients with cancer. Nancy Keating, MD, MPH, from Dana-Farber/Brigham and Women's Cancer Center remembers her first interactions with Dr. Hurria. "She made it a priority for the 2 of us to meet in person, reflecting her desire to really understand each member of the panel and think about how they might best contribute to the group," she said "She proceeded to outline a very ambitious agenda for refreshing the existing guidelines and addressing the guidelines' many gaps. I learned a great deal from Arti about how to support a group's collaborative effort to achieve bold goals."

Dr. Hurria made it a priority to include many junior faculty panel members in the guideline development work and allowed them to shine, growing the next generation of clinician-scientists in the expanding field of geriatric oncology. She was a true mentor and teacher at heart. Many of us owe our success and academic growth to her mentorship. Ishwaria Subbiah, MD, MS, from The University of Texas MD Anderson Cancer Center, stated, "She nurtured many early-career

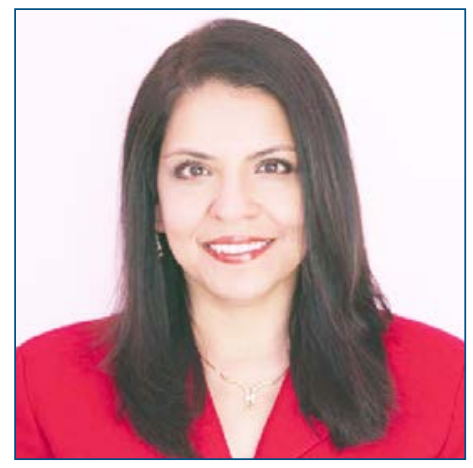

\section{ARTI HURRIA, MD}

Arti Hurria, MD, was a much-admired geriatrician and oncologist. At the time of her death, she was the George Tsai Family Chair in Geriatric Oncology, director of the center on Cancer and Aging, co-lead of the Cancer Control and Population Science Program, vice provost of clinical faculty, a professor of the Department of Medical Oncology \& Therapeutic Research, and a medical oncologist at City of Hope National Medical Center.

Earlier in her career, she completed the Harvard Geriatric Fellowship Program, followed by a hematology-oncology fellowship at Memorial Sloan Kettering Cancer Center. She subsequently joined the faculty at Memorial Sloan Kettering, where she served as coPrincipal Investigator on an institutional NIH P20 grant "Development of an Aging and Cancer Center." In 2006, Dr. Hurria joined City of Hope. In addition to her responsibilities at City of Hope, she had served as the President for the International Society of Geriatric Oncology from 2012 to 2014 and served as Chair of the NCCN Senior Adult Oncology Panel (now "Older Adult Oncology") from 2011 to 2016. She had also been co-Vice Chair of the Alliance Cancer in the Elderly Committee, and Editor-in Chief of the Journal of Geriatric Oncology. Dr. Hurria was also founder of the Cancer and Aging Research Group (CARG), a coalition that conducts multi-center geriatric oncology research studies and mentors junior faculty in geriatric oncology. Dr. Hurria was a recipient of the Paul Beeson Career Development Award in Aging Research.

doi: $10.6004 /$ jnccn. 2019.0004

The ideas and viewpoints expressed in this commentary are those of the author and do not necessarily represent any policy, position, or program of NCCN. 
geriatric oncology investigators like me. She was generous with her time and always provided prudent counsel." Similarly, Noam Vanderwalde, MD, of the West Cancer Center/ University of Tennessee recalled, "Arti had a way of making everyone feel as if they were extremely important to her, regardless of how closely you worked with her."

Her involvement and close mentoring continued after she stepped down from chairing the NCCN Older Adult Oncology Panel, with continued support and advice on how to further advance our guidelines. She was always available for a conversation, and regardless of how hard the challenge seemed, she made us feel as if we are the right team to get it done.

There is a warm place in all of our hearts for Arti Hurria, which we will continue to cherish as we work to hon- or her legacy. "She has taken us down a road that together we will continue to travel on, remembering her fondly along the way," Ms. Burhenn added. As a guideline panel, we will continue to focus on developing tools to guide practicing oncologists in the assessment and evaluation of older patients with cancer, and promote much needed research in this understudied group of patients. We will work to achieve Dr. Hurria's aspiration to have a seamless link between the older adult guidelines and guidelines developed for specific types of cancer. She will remain our guide and our inspiration as we continue to engage in research, teaching, mentoring, and advocacy to improve the care of older adults with cancer. We are all thankful to have met and worked with such a great role model and a legend in this field. 